of citric acid, "as much acetic acid, and 3 grammes of pyro-gallic acid; an atom of nitrate of silver is added. The negative is placed in this developer and left in it till the coloration of the image becomes sufficiently intense ; then it is passed into a bath of hyposulphide of soda, then washed and dried between leaves of blotting paper. It is then proof against heat and moisture, and may be kept indefinitely in an album. The apparatus itself is so constructed as to be capable of remaining two days in water, even in sea water, without deterioration.

THF most important papers read at the meetings of the Khark ov Society of Naturalists duxing 1876 are:--"On the Mechanism of the Respiration of Birds," by N. Byeletsky; "On Respiration of Roots," by A. Zaykevich ; two entomological papers on the province of Kharkov, by P. Ivanov and V. Yaroshevsky; "On the Arachnidæ Arenee, and on the Conjunction of Chlanydomonas pulvirulus and Stigloclonizm," by L. Reinhard; and the continuation of the "Flora of Ukraina" (Compositece to Salsolaceee), by K. Gornitsky.

Mr. Thomas S. CAyzer, head-master of Queen Elizabeth's Hospital, Bristol, known as the author of one thousand arithmetical tests and of other approved school-books, has made a complete collection of the principal passages in Latin authors that refer to our island, and editing them with vocabulary and notes, is about to issue the volume through Messrs. Griffith and Farran, as a Latin reading-book, illustrated with many woodcuts and a map, under the title of "Britannia."

THE additions to the Zoological Society's Gardens during the past week include a Slow Loris (Nycticebus tardigradus) from India and a Cape Hedgehog (Erinaceus frontalis) from West Africa, received in exchange; a Wedge-tailed Fruit Pigeon (Treron sphenura) from India, presented by Mr. A. H. Jamrach; an Egyptian Gazelle (Gazella dorcas) from Barbary, presented by Capt. J. Graham.

\section{AN ALGERIAN INLAND SEA}

$\mathrm{S} \mathrm{S}$ our readers are aware several schemes have recently been $A$ before the public for the creation of an inland sea in North Africa, one of the most ambitious and most impracticable of these being the flooding of a great part of the Sahara. Another scheme which has engaged the attention of the French Government for some time is much more feasible and likely to be attended with good results. The Report of a Commission on the plan proposed by M. Roudaire for the creation of an inland Algerian sea was recently presented to the French Academy of Sciences by M. Favé, and as it contains several points of scientific in terest, we propose to lay it before our readers.

Since the French domination was extended in the province of Constantine as far as the town of Biskra, the attention of several observers has been turned to the very marked depressions of the soil, which commence at about 50 kilometres to the south of Aurès, that is, to the border of the Sahara, and extending from east to west. M. Virlet d'Aoust supposed, in 1845 , from the measurement of the slope of a river discharging into the Chott (or marshy lake) Mel-Rir, that the bottom of that chott must be below the level of the Mediterranean. In $1849 \mathrm{M}$. Dubocq, a mining engineer, proved, by a very numerous series of barometric observations, published in 1853, that singular anomaly, which Capt. Vuillemot confirmed in 1856 . It was reserved to Capt. Roudaire, to render the fact incontestable and to determine the depth with almost complete accuracy.

After having taken for his starting-point the embouchure of one of the two small streams which fall into the sea at the bottom of the Gulf of Gabes, M. Roudaire traversed the steppe of Gabès, 46 metres high, then arrived at the depression of a chott the surface of which he estimated, at sight, at 5,000 square kilometres. He then reached, by crossing a second elevation of 45 metres, that of Kritz, the depression of the Chott Rharsa, situated to the east of the Chott Mel-Rir, from which it is separated only by two elevations of small height. These two slight elevations bound the Chott Asloudj, the surface of which does not exceed 80 square kilometres. The surface of the Chott Rharsa has been estimated at I, 350 square kilometres; that of the Chott Mel-Rir, which has been surrounded by a polygon of levelling, contains 6,700 square kilometres. The three basins which form the Chotts El Djerid, Rharsa, and Mel-Rir have not yet been surveyed in all directions ; but M. Roudaire has concluded from various observations that the mean depth of the two Chotts Mel-Rir and Rharsa must not be below 24 metres. The small Chott El Asloudj, which is intermediate, has a mean depth of only from one to two metres, which makes him regard it as a slightly elevated barrier between the two great lakes. If it be admitred that this barrier could be pierced by a trench of suitable depth, and that the water of the sea were led from the Gulf of Gabès to the entrance of the Chott Kharsa, the sea would fill that chott, as also the Chott Mel.Rir, and the depth of water would be sufficient in the two lakes for the navigation of all vessels. Articles of commerce could be transported thence to all parts of the world without any re-embarkation.

Such is the starting-point of a project for an inland sea which M. Roudaire has had constantly in his mind during all his labours: he is confident that the execution is an easy matter, without allowing himself to be discouraged by any obstacle. The enterprise, supposing it to be realised, would certainly not present commercial advantages comparable in any respect to those resulting from the canalisation of the Isthmus of Suez. The products of Central Africa, transported by camels across the desert do not seem to be sufficiently abundant to furnish freight for a large number of vessels. There is no doubt, however, that if the products of Central Africa had no longer to bear the expense of so long a carriage by land, their price would be notably lowered and their consumption increased. But indeed it would be impossible to estimate the benefits which in the future would result from the creation of such an inland sea. Considerations of another kind leave no doubt, M. Favé thinks, as to the improvements which would result from an inland sea covering 13,230 square kilometres, from a climatic point of view and in relation to the fertility of the soil.

Prof. Tyndall was engaged for some years in determining the action which the vapour of water exercises upon radiant heat. He has proved that even with complete transparency to light, the vapour of water absorbs radiant heat to a very notable extent. The vapour of water possesses that absorbent property much more than the air with which it is mixed, in however small a proportion; and its absorbent power increases very nearly in proportion to its mass. Prof. Tyndall has not failed to bring out the influence which the invisible vapour of water contained in the air exercises upon temperature, both during day and night, and he has been able hence to draw immediate conclusions as to its influence upon the life of plant:. After having measured directly the quantity of heat absorbed by very minute quantities of vapour of water mixed with air in his experimental tubes, he feels authorised to speak thus:- "Considering the earth as a source of heat, it may be admitted as certain that at least ro per cent. of the heat which it tends to radiate into space is intercepted by the first six feet of moist air which surrounds its surface." Prof. Tyndall hence draws this conclusion :"The suppression, during a single night of summer, of the moisture contained in the atmosphere which covers England would be accompanied by the destruction of all the plants which frost kills."

It is not only the cold of night which is increased at the surface of the ground by the dryness of the air, but also the heat of day; so that the variations of temperature produced in twenty-four hours are sometimes very great and very prejudicial to the vegetation of a great number of plants. We may apply these considerations to the region of the chotts, where M. Roudaire, in his expedition of $1874-5$, found heat of $25^{\circ}$ (C.) during the day, and cold of $8^{\circ}$ below zero during the night. After that we need not be longer surprised that the lands comprised between the slopes south of Aurès and the chotts produce very little, however favourable in themselves they may be to vegetation. If we admit with $M$. Roudaire, agreeing in this point with all explorers of the chotts, that their cavities have at one time formed salt lakes, dried up gradually during the historic period, we shall obtain an explanation of the changes in the production of the soil of the province of Constantine, and of Tunis since the epoch of Roman domination, when the province of Africa was much more populous and much more fertile than at present.

M. Roudaire has sought to find results of observations from which he might conclude what would be the depth of the bed of 
water evaporated after the creation of the inland sea. He has found this information in the experiments made at the Bitter Lakes traversed by the Suez Canal. At the time of the fillingup of the Bitter Lakes, a waste-weir was constructed intended to regulate the introduction of the water of the Mediterranean. From July 7 to 14 the weir was wrought with only a small number of sluices raised, and the level of the lakes remained stationary. The introduction had been regulated to about $3,540,942$ cubic metres, or, in round numbers, 4,000,000, cubic metres per day. This figure, then, gives the quantity of water absorbed by evaporation which, according to the extent of surface, produced a lowering of the level of from $003 \mathrm{~m}$. to $.0035 \mathrm{~m}$. during twenty-four hours, and that in the hottest month of the year. All the observations made since that time have given essentially the same results, and we must admit, with the engineers of the Suez Company, a general mean of $003 \mathrm{~m}$. per day, or I $\mathrm{m}$. per year. M. Roudaire has added, as a conclusion to be drawn from this bearing on his project:- "The basin of the chotts and the Isthmus of Suez being situated nearly under the same latitude, and possessing a climate absolutely analogous, we must admit that the evaporation which will be produced on the inland sea will be the same as that which has been observed on the Bitter Lakes. The figure ${ }^{\circ} 003 \mathrm{~m}$. is the general mean of the year. The observations which we have made in the chotts with Piche's evaporometer have proved to us that this figure is at least doubled during the sirocco."

Not only would the vapour of water thus diffused through the air serve as a reservoir for the heat emanating from the earth or the sun, but it would have still another mode of action for effecting climatic modifications. The air and its vapour brought into contact with the elevated and therefore cool parts, the Aurès mountains, and other mountains of Algeria, would have their temperature lowered on account of that cause, and the effect would be increased by the radiation of the vapour of water into space; for that radiation would operate almost without check at a height where the air from above, and therefore less dense, is cold and dry. Under the influence of this double cause the moisture would be condensed into rain or snow, and would serve to feed the watercourses which would permanently flow in the beds at present dry during a great part of the year. We should see issuing from the ground, from the same cause, sources which do not now exist. The moisture, discharging itself along the lines of watercourses, would extend its influence on the two slopes of the mountains to countries at a distance from the chotts. We can perceive by calculations the volume and the weight of the masses of water set in motion by evaporation, that these considerations are not chimerical. The 13,230 square kilometres give 39,690,000,000 kilogrammes of water per twenty-four hours, raised by evaporation, i.e., 39,690,000 cubic metres. It will be seen that there is here something to form sources and feed streams or rivers. M. Roudaire has calculated that the quantity of vapour diffused in air whose barometric pressure is $760 \mathrm{~m}$., and the temperature $\mathrm{I} 2^{\circ} \mathrm{C}$, , would cover the surface of Tunis and Algeria with a layer of half-saturated air, 24 metres in height. Let us remark that this calculation includes only the quantity of vapour formed during twenty-four hours. The south wind known as the sirocco, at present so destructive because it is exceedingly dry, would produce on the surface of the lakes an evaporation much greater than that mean, and would, moreover, lose many of its hurtful effects. In fact, this same wind, which destroys the vegetation of Algeria, has a fertilising influence on the territory of France, because of the moisture with which it becomes charged in crossing the Mediterranean.

Advantages so considerable, which would result from the introduction of the water of the sea into the chotts, explain and justify the perseverance with which $M$. Roudaire has pursued the idea without allowing hiruself to be arrested by any of the difficulties which have presented themselves. The greatest of the difficulties, M. Favé thinks, proceeds from the fact that the Chott El-Djerid, the nearest to the Gulf of Gabès, has not, like the others, the bottom of its basin below, but above, the level of the sea. The surface of the ground is undulating; it rises to 20 metres, or even more, at certain points, and descends to zero at other points. M. Roudaire has estimated, somewhat vaguely, that the mean height of the bottom may be about 6 inetres above sea-level. Notwithstanding this obstacle, M. Roudaire does not renounce the hope of being able to make the water of the sea reach the Chott El-Djerid in order to turn it afterwards into the other two chotts. He believes he has found a support for this in the nature of the bottom, or, to speak more exactly, in the existence of a water-bearing bed situated at a small depth below the ground.

The Commission, of which M, Favé is the mouthpiece, with. out pronouncing definitely on the project of $M$. Roudaire, sufficient data for this not being forthcoming, strongly recommend that active steps be taken to obtain more accurate measurements and other data. The facts which he has adduced they think sufficient to justify serious attention being paid to his proposal, and recommend that the thanks of the Academy be accorded to $M$. Roudaire for his valuable labours. To these recommendations the Academy agreed.

We should state, however, that MM. Dumas and Daubrée, members of the Commission, are not able to give their entire consent to the recommendation of M. Favé's report. They think that the obstacles to the accomplishment of the scheme are much more serious than have heen estimated, and regard the industrial and climatic results anticipated as, to a considerable extent, hypothetical, M. de Lesseps, however, gives his entire concurrence to the scheme of M. Roudaire, and believes in its practicability and the favourable results that would follow its realisation.

\section{UNIVERSTTY AND EDUCATIONAL INTELLIGENCE}

Science and Art Department.-The Committee of Council on Education have just issued an important circular on instruction in practical chemistry and in physics. My Lords direct that $\S \S X L V$. and LXXI. of the Science Directory be cancelled and that the following rules be substituted:- - r. Payments of Il. IOs. and $\mathrm{I} l$. for the first and second class in the elementary stage, and of $4 l$. and $3 l$. for the first and second class in the advanced stage and honours, will be made on the results of in. struction in practical chemistry. They will be claimable accord. ing to the same rules, and subject to the same deductions on account of previous success as the ordinary payments. These payments will be made on condition-(a) That there be a good laboratory-being a room, or part of a room, exclusively devoted to the purpose of the study of practical chemistry--properly fitted with gas and water supply, (b) That the student on whom the payment be claimed have received twenty-five lessons at least in laboratory practice since his last examination, each lesson being an attendance of at least one hour and a half's duration on a separate day. (c) That a register of the attendance of the students at the instruction in practical chemistry be kept duly posted up from day to day. 2. Elementary Stage. - In this stage the knowledge of the students will be tested by special questions set with the ordinary examination paper ; but no payments will be made if the laboratory be not furnished with all the apparatus necessary for the individual practice of each student in practical chemistry, and if systematic instruction in practical chemistry be not given. Any student on whom it is intended to claim payments in this stage may be cailed on by the Inspector of the Department, when visiting the laboratory, to repeat some of the experiments, specified in the Science Directory in the syllabus for the first stage of inorganic chemistry, which he has had an opportunity of witnessing. 3. Advanced Strge and Honours, The results of the instruction in these stages will be tested by a special examination in qualitative analysis to be held on a Saturda during the ordinary May examinations, and lasting, for the advanced stage from 6 P.M. to 10 P.M., and for honours from 2 P.M. to IO P.M. Payments can only be claimed in these stages provided-(a) That the laboratory be fitted up with a separate working place for each student. (b) 'That each student be provided with a complete set of apparatus and chemical tests (as enumerated in Science Form No. 402) kept separate, and in good working order, on the shelves, and in the cupboard or drawers at his own tab!e. (c) That the laboratory be also furnished with apparatus for general use, consisting of at least the articles of which a list will be found on Science Form No, 402 . From the reports of the examiners and of the inspectors it appears that instruction still continues to be given in physics without a sufficient amount of apparatus to illustrate the teaching of these experimentai sciences. My Lords cannot allow examinations to be held in schools where instructions of such a superficial and perfunctory nature is given. They therefore direct that in 1878 no classes be examined which are not furnished with apparatus at least sufficient to illustrate some of the more important experiments; which apparatus the teacher may be called upon by the Inspector of the Department to show his ability to use. 